\title{
Expanding veterinary therapeutic access
}
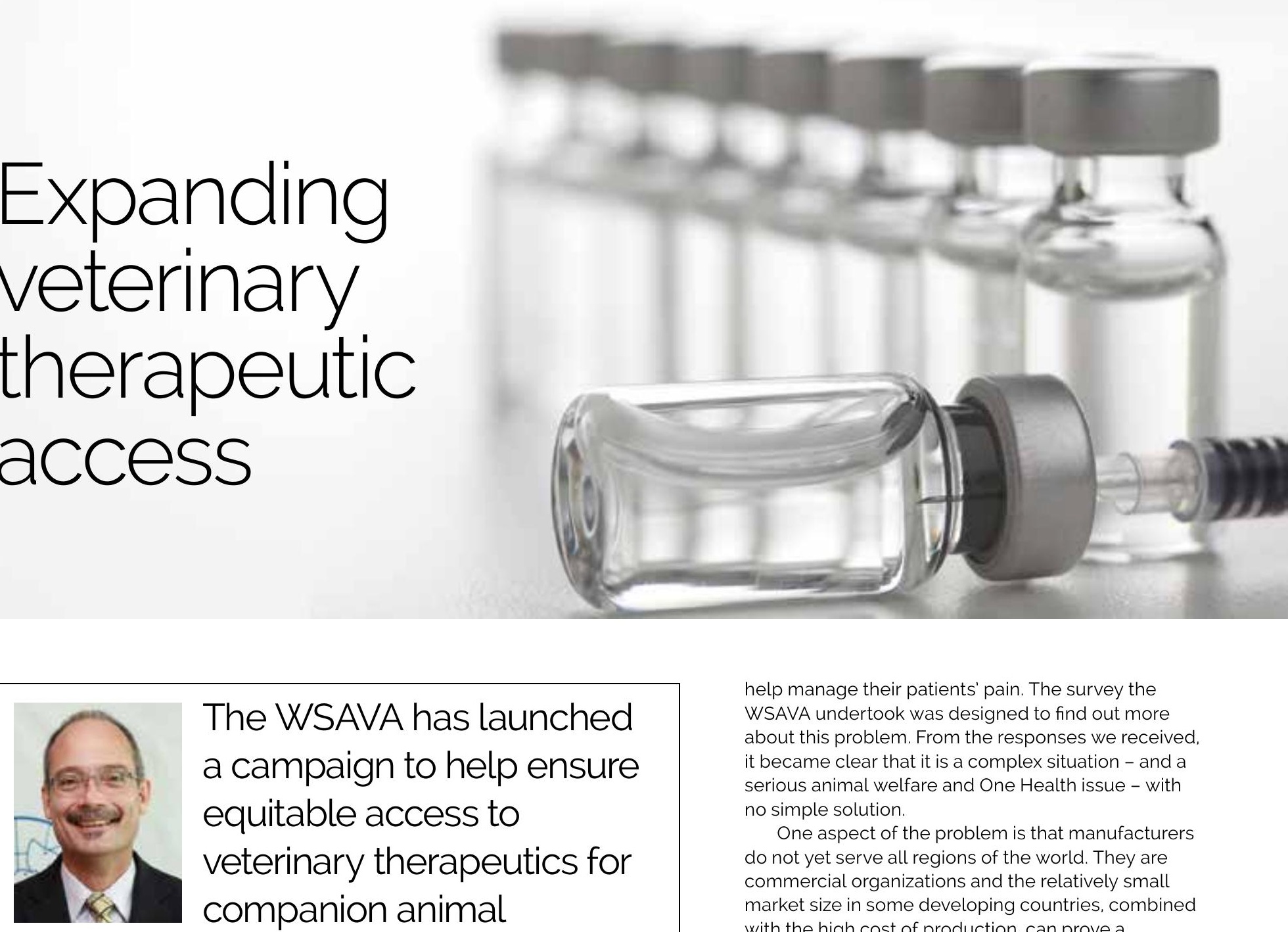

\section{The WSAVA has launched a campaign to help ensure equitable access to} veterinary therapeutics for companion animal veterinarians wherever they work in the world. WSAVA President Dr Walt Ingwersen, explains why.

$\mathrm{n}$ a member survey conducted by the World Small Animal Veterinary Association (WSAVA) in 2016, ${ }^{1}$ $75 \%$ of respondents indicated that the problems they experienced in accessing veterinary pharmaceuticals hindered their ability to meet the needs of their patients. In $20 \%$ of cases the impact on the quality of care they provided was 'severe'.

As veterinarians, access to the diagnostics and therapeutic modalities we need is the foundation of the care we offer to our patients and, for those of us working in the developed world, it's not something we think twice about. In fact, as new products are launched and treatments advance at a dizzying rate, we are often spoilt for choice.

However, for thousands of our companion animal colleagues working in Eastern Europe, Asia, Africa and Latin America, it's a different world with many of them lacking access to even basic therapeutics to help manage their patients' pain. The survey the WSAVA undertook was designed to find out more about this problem. From the responses we received, it became clear that it is a complex situation - and a serious animal welfare and One Health issue - with no simple solution

One aspect of the problem is that manufacturers do not yet serve all regions of the world. They are commercial organizations and the relatively small market size in some developing countries, combined with the high cost of production, can prove a significant barrier

The regulatory environment in developing countries is also an issue. Authorities in some countries allow for 'regulatory discretion' in the use of licensed pharmaceuticals in animals in an 'extra label' fashion or enable medicines to be imported from other countries through 'emergency drug release' (e.g. Cascade in the EU) - but, while this sounds a pragmatic solution, responses from our survey revealed that the amount of time required to navigate the bureaucracy and paperwork of these regulations is a major obstacle in itself.

While using the internet to order in pharmaceuticals is emerging as a solution to a lack of product availability in particular countries, it is also raising concerns as to a potential lack of adherence to scripting practices and poor regulatory oversight. It also has the potential to undermine the relationship between veterinarians and their clients and to fuel the market for counterfeit therapeutics.

As a global association representing more than 200,000 companion veterinarians, the WSAVA has been working in this area for some time, for instance, through our Global Pain Council's campaign against the international scheduling of ketamine. The issue of restricted access to veterinary pharmaceuticals however is a long-standing problem and, given the continuing frustration of many of our members at the difficulties they experience, it's time for action.

To drive our campaign, we have formed a Therapeutics Guidelines Group (TGG), comprising 
individuals with global expertise in this area under the chairmanship of Professor Luca Guardabassi. Luca, a Diplomate of the European College of Veterinary Public Health (ECVPH), is professor at the Faculty of Health and Medical Sciences, University of Copenhagen and is an internationally recognized One Health microbiologist specializing in antimicrobial resistance.

Luca and his team are monitoring the issue of global access to veterinary medicines and working on a range of activities including:

- Developing minimum standards for a veterinary hospital pharmacy to ensure it can support a veterinarian's ability to provide an appropriate standard of care

- Monitoring issues relating to access to veterinary therapeutics and recommending specific solutions using an evidence-based approach

- Engaging global stakeholders to raise awareness of the issue and build a collaborative approach to resolve issues around therapeutic access, as well as antimicrobial resistance and other related issues.

As a first step, the WSAVA's Executive Board has already created a position statement on the issue and we are calling on our member associations and on other veterinary associations to support it. We are delighted to say that many already have.

The WSAVA's campaign will greatly benefit veterinarians around the world, especially in the developing countries. We are very pleased to be associated with it.

\section{Dr S Abdul Rahman, Executive Director of the Commonwealth Veterinary Association}

We expect many more to express their support during the 43rd WSAVA World Congress which will be in Singapore from 25-28 September, 2018. We are also urging our individual members to support this position statement. If you would like to support our work in this area visit www.wsava.org/Committees/Committees/ Therapeutics-Guideline-Group

During this year's WSAVA World Congress we will be hosting a stakeholder summit, which will bring together regional experts to discuss potential solutions. Following this discussion we will announce the next steps in our campaign to tackle what is clearly a serious global animal welfare issue. We urge the wider veterinary community to join us in helping to bring about much needed change.

\section{WSAVA Position Statement}

'Ready access by healthcare professionals to pharmaceuticals (e.g. medicines anaesthetics/analgesics, etc), biologicals (e.g. vaccines, etc), parasiticides, and antiseptics is one of the key pillars of appropriate patient care, whether in human or veterinary medicine. Inequities in availability and access exist between various regions of the world for a variety of reasons. We call upon key stakeholders (regulatory authorities, manufacturers, and healthcare professionals) to seek solutions that would broaden access while maintaining the sanctity of the veterinary-client-patient +/pharmacist relationship, where warranted.

\section{Associations which have expressed their support for the WSAVA campaign}

- The Federation of European Companion Animal Veterinary Associations

- The Federation of Asian Small Animal Veterinary Associations

- The Federation of Asian Veterinary Associations

- The Federación Iberoamericana de Asociaciones Veterinarias de Animales de Compañia

- The Commonwealth Veterinary Association

- Fédération des Associations Francophones Vétérinaires pour Animaux de Compagnie

- HealthforAnimals

\section{Case studies}

Dr Olatunji Nasir is Medical Director and CEO of the Truthmiles Animal Hospital in south west Nigeria and Vice President of the Small Animal Veterinary Association of Nigeria.

"Companion animal veterinarians in Nigeria face a Herculean task in trying to access everything from basic medical consumables, such as syringes and needles, right up to veterinary drugs. Registration fees are very high because they are the equivalent of what is charged for human drugs despite the fact that the volume used is much lower. The process of registering a new drug can also take up to 36 months - and this is feeding a demand for sub-standard products which are smuggled into the country. The procedures for importing drugs are also cumbersome and impractical."

Dr Dayani Siriwardane is a member of Society of Companion Animal Practitioners of Sri Lanka (SCAP) and Director at Pet Vet-small animal practice in Colombo.

"In Sri Lanka, demand for small animal veterinary medicine is increasing but importing drugs is complex. Often the user permit is only valid for 6 months so we then have to go through the process again. For large quantities of drugs, the process becomes very lengthy and expensive.

"We are also told that our market is too small to make it viable for many manufacturers. This situation must change. While demand may not be huge today, the number of companion

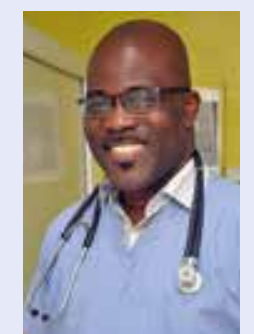
animals in Sri Lanka is increasing and the new generation of vets wants to use the latest techniques and have access to the latest drugs. If companies invest now, the market will grow and we can fulfil the welfare needs of our patients which is very difficult at the moment."

\section{Dr Ed Unson is former President of the Philippine Animal Hospital Association and is in practice in Makati City, Metro Manila, in the Philippines.}

"The 'economics' of importing drugs mean that veterinary pharmaceutical companies don't register them for use in the Philippines because our animal industry is more focused on livestock and food-producing animals. It is frustrating because our small animal veterinarians are now working hard to promote continuous education and animal welfare groups are lobbying for higher animal welfare standards. The pet population is growing fast in South East Asia yet drug companies still do not see our markets as opportunities.

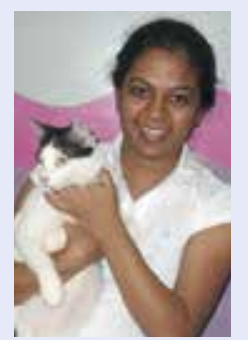

"On the few occasions that a company does decide to register a drug with the Food and Drugs Agency, the process takes 2-5 years with many complex stages and, sometimes, plant visits in the USA or Europe. Some veterinarians try to bring drugs in but Philippine Customs makes this difficult and generally confiscates them, even if they are not dangerous.

"Our lack of access to drugs makes our practice look archaic, especially when both we and our clients can see the range of products available to our colleagues elsewhere on the internet, while we are forced to use one drug for a range of purposes. Urgent change is needed. 